\title{
The Influence of E-Commerce Live Streaming on Lifestyle Fit Uncertainty and Online Purchase Intention of Experience Products ${ }^{1}$
}

\author{
Zhenjiao Chen \\ Beijing Institute of Technology \\ Beijing, China \\ sharon2009@bit.edu.cn
}

\author{
Ron Cenfetelli \\ University of British Columbia \\ Vancouver, Canada \\ cenfetelli@sauder.ubc.ca
}

\author{
Izak Benbasat \\ University of British Columbia \\ Vancouver, Canada \\ Izak.benbasat@sauder.ubc.ca
}

\begin{abstract}
Deriving from the existing research in the product uncertainty literature, we propose a new type of uncertainty that is an important predictor of purchase intention on e-commerce websites: lifestyle fit uncertainty. This uncertainty is distinct from uncertainties regarding description or performance, and targets the uncertainty that results from not knowing how much a product will help a customer reach their broader life goals and values. By integrating mean-ends chain of lifestyle (MECL) theory, socialized charismatic leadership (SCL) theory and product uncertainty theory, we explore how ITmediated marketing service content of e-commerce live streaming mitigates lifestyle fit uncertainty. We also identify ICT-enabled information retrieval capabilities in live streaming platforms as moderators which regulates the effects of IT-mediated marketing service content on lifestyle fit uncertainty.
\end{abstract}

\section{Introduction}

Despite the popularity of e-commerce in recent years, the conversion rates (percentage of visitors who make purchase decisions) of e-commerce websites are, on average, only $3 \%$ globally ${ }^{2}$. Customers are especially hesitant to buy experience products, such as cosmetics and clothes, online [1]. As everyone pursuits a unique lifestyle, MECL theory [2] claims that a consumer's purchase decision is driven by his lifestyle, which refers to a specific pattern of individual behaviors (e.g., daily consumption behaviors) to meet one's unfilled needs and further realize one's life values (i.e., ideal life states) [2, 3].

Lifestyle-driven purchase decision making is a process of assessing whether the usage of a product helps to realize a life value/goal. In such a process, the information of product attributes, consumption experience and life values are necessary so that consumers can tell whether the product attributes bring them satisfactory consumption experience that helps to realize their ideal life states (i.e., life values) $[2,4,5]^{2}$. According to information asymmetry perspective $[6,7$, 9], if being lack of the necessary information, consumers will have a sense of uncertainty in decisionmaking. Our study develops a new concept to describe this kind of uncertainty, lifestyle fit uncertainty. It is defined as the degree to which consumers can't assess whether the consumption experiences of product attributes matches their life values. Accordingly, consumers are less likely to buy a product if not sure whether it matches their life values or not.

As consumers can't try experience products online and don't have related consumption experience $[8,9]$. Lifestyle fit uncertainty is especially high and is a major obstacle that inhibits online consumers to buy experience products. Thus, this paper explores how to reduce lifestyle fit uncertainty of experience product in the online context; and "product" in the following paragraphs refers to experience product.

Although, customer uncertainty ultimately inhibits buying online [10], extant e-commerce literature focuses on reducing product uncertainty, product fit uncertainty and seller uncertainty online [8, 9, 10]. These studies demonstrated that these uncertainties can be significantly reduced by online product description, third-party assurances, internet-enabled systems, reputation and trust. Despite that lifestyle fit uncertainty may reduce online purchase intention, rare studies worked on it and explored how to mitigate it.

The negative effects of lifestyle fit uncertainty in online markets are especially reflected in inhibiting consumers' purchase intentions. Only if a product matches with a consumer's lifestyle and the consumer relies on it to maintain an ideal life state, he/she will purchase it in daily life [3, 11]. Marketing scholars [3, $11,12,13]$ found that lifestyles affect consumption experience of products and consumers' loyalty to a product. In offline marketing, the lifestyle marketing

\footnotetext{
${ }^{1}$ This paper is sponsored by the National Natural Science Foundation of China No.71471017.

2 《2016 Marketing Research Report on Live Streaming in China》http://wreport.iresearch.cn/uploadfiles/reports.
} 
approach [2, 3] (i.e., an approach involves segmenting consumers into different groups on the basis of different lifestyles, promoting a product in terms of how it will allow the targeted consumer group to pursue its desired lifestyle) is widely adopted by some best-selling brands (e.g., Ikea and Starbucks) to mitigate consumers' lifestyle fit uncertainty and improve their purchase behavior as well as loyalty.

In 2016, e-commerce live streaming services, as a new online marketing mode, occurred in Chinese ecommerce websites (e.g., Taobao, Mogujie, and Jumei), which increased the conversion rate of Taobao by up to $30 \%{ }^{3}$. The possible reason for the success of such a service is that its distinguished characteristics help to mitigate lifestyle fit uncertainty for online consumers, which we next describe. The first characteristic is that its service content is IT-mediated and lifestyle-centric. The service content is IT-mediated as it is a marriage of a "grassroots" Internet celebrity's behaviors (see Picture 1) and information communication technology (ICT) capabilities; that is, various ICT capabilities of a living streaming platform assist the Internet celebrity to transmit marketing information for online viewers (i.e., consumers) [15]. Grassroots Internet celebrities are ordinary people who broadcast live streaming shows and are acknowledged by lots of fans (i.e., online viewers) as having similarities in life values and consumption preferences with the fans. Some of them are well-trained with product knowledge and marketing skills, and work at e-commerce websites as marketer influencers. Thus, we defined IT-mediated service content of e-commerce live streaming as the functions of transmitting marketing information to assist online viewers in making purchase decisions [14].

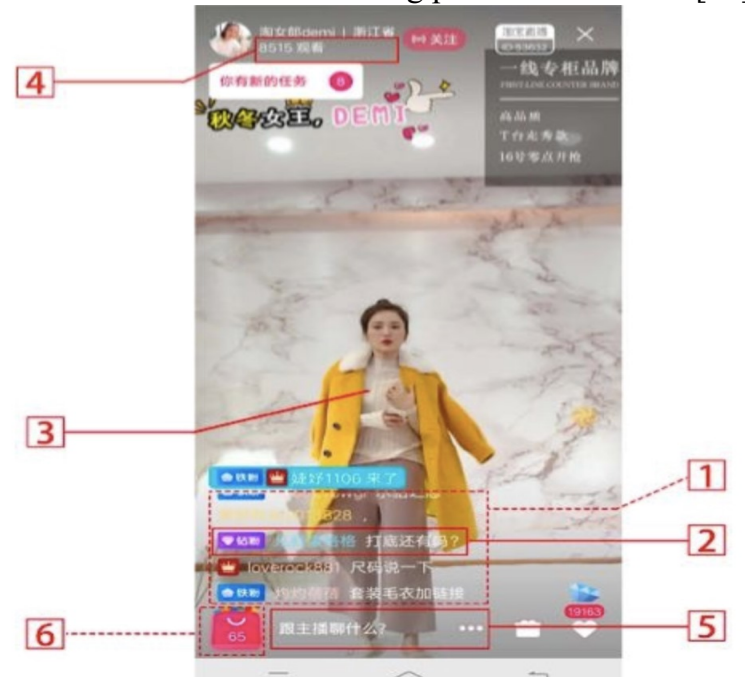

Notes: 1- Public scrolling text screen; 2- Message from online viewers; 3- Internet celebrity; 4- the number of online viewers (8815); 5- Dialog box; 6- Linkage of product presentation

Picture 1. The screenshot of a live streaming show
Moreover, the service content is lifestyle-centric. Lifestyle-centric marketing is a mechanism to allow a product to be promoted in terms of how it will allow a person to pursue a desired life values [2, 3]. The service content of e-commerce live streaming presents product attributes, transmits consumption experience and life values. The information facilitates consumers to make lifestyle-centric purchase decision $[2,4,11]$.

The second characteristic is reflected in ICTenabled information retrieval system that enables online viewers to search and acquire the information delivered by the service content. Specifically, there is often a public scrolling text screen in a live streaming show. The information retrieval system allows an online viewer to type message (e.g., an inquiry) in a dialog box. The message is shown on the public screen and can be seen by the internet celebrity and all online viewers. Then the internet celebrity responds to the inquiry in the show so that the viewer obtain needed information. Meanwhile, other online viewers who is watching the show also obtain the information and select what is useful for them to facilitate their purchase decision-making.

The above system is afforded by two ICT capabilities: interactivity and communication visibility $[16,17]$. (1) Interactivity enables an online viewer obtain the needed marketing information (e.g., value, consumption experience or product attributes) by synchronously communicating with the internet celebrity. (2) Communication visibility enables an online viewer, as a third party, to get the needed information by observing communication between other online viewers and the internet celebrity. Some inquiries from the other viewers presented on the public screen were similar as his own. From those dialogues, he obtained needed marketing information.

It is important to note that the ICT-enabled information retrieval system would not be practical in the offline world. For instance, in a live streaming show, the number of online viewers is very large, ranging between 1000 to 20000 . In an offline context, it is impossible for an internet celebrity to interact with so many viewers to deliver their needed information. However, in the online context, the two ICT-enabled information retrieval capabilities allow all of these viewers get their needed marketing information synchronously from the service. If more people obtain lifestyle-centric marketing information, the more purchase intention will be motivated. Specifically, "ICT enabled interactivity" allows a small portion of online viewers (e.g., 1\%-10\%) to "type on the public screen" and "chat with the internet celebrity" to get more information. "ICT-enabled communication visibility" allows the remaining online viewers $(90 \%$ $99 \%$ ) to only watch "the public screen" as well as "the

3 《Should all online sellers become broadcasters of e-commerce live streaming?》http://www.sohu.com/a/105968044_221415. 2016, 07, 14. 
dialogues" between the small portion of online viewers and the internet celebrity to obtain needed information.

Enlightened by the distinguished characteristics of live streaming services, the objective of this research is to explore the following research questions: What is the nature of lifestyle fit uncertainty in e-commerce websites? What is the effect of lifestyle fit uncertainty, relative to the other types of product uncertainty, on consumers' purchase intention in e-commerce websites? How does IT-mediated lifestyle-centric marketing service contents help to mitigate lifestyle fit uncertainty? Why does ICT-enabled information retrieval capabilities moderate the effect of the service contents on lifestyle fit uncertainty?

The remainder of this article is organized as follows. The section that follows presents the literature review. Based on the theories, we propose the research model and develop propositions. Next, we discuss the theoretical and practical implications.

\section{Literature review}

\subsection{Nature of lifestyle fit uncertainty}

The concept of uncertainty derives from the economic field, and refers to partial information [18]. Product uncertainty theory [3] defined uncertainty in ecommerce field as unpredictable transaction outcomes due to imperfect information. A review of uncertainty literature shows that there are different types of uncertainty.

First, uncertainty may be caused by imperfect information of sellers, namely seller uncertainty, which is defined as the buyer's difficulty in predicting whether the seller will act opportunistically because of failing to assess the seller's true characteristics and act in future. Many studies identified factors which reduce seller uncertainty, such as feedback ratings, comments, and market assurances (for a review, see [10]).

Second, uncertainty may be caused by imperfect information of products [9]. Product uncertainty includes description uncertainty and performance uncertainty. Description uncertainty refers to the inability of e-commerce websites to perfectly present the product characteristics due to limited internet technologies and the seller's lack of product expertise [9]. For example, e-commerce websites have difficulty in accurately describing "the taste of a food". Imperfect product information (e.g., experience attributes) will lead to performance uncertainty, defined as the degree to which a consumer has difficulty in assessing how the product will perform in future (e.g., "whether the food has a good quality") [9].
Recently, scholars [10] proposed the concept of product fit uncertainty and defined it as the degree to which a consumer cannot assess whether product attributes match his preference. A consumer's preferences makes him more likely to desire some products or product attributes than others [19].We need more sources of information to reduce product fit uncertainty than to reduce product uncertainty. For example, before a daughter buys shoes for her mother online, product fit uncertainty may be caused by lacking of information related to 1) product attributes (e.g., whether the quality of shoes is good); 2) consumer preference (e.g., her mother's preference); 3) cues to infer the fit between product attributes and consumer preference (e.g., whether her mother feels well if wearing the good-quality shoes) [10].

A comprehensive review of online uncertainty shows that seller uncertainty has been adequately theorized, but product uncertainty and fit uncertainty in the online context remain inadequately theorized [9, 10]. Thus, this study focuses on product uncertainty and fit uncertainty. We propose the new concept of lifestyle fit uncertainty, defined as the degree to which a consumer cannot predict whether the consumption experience of product attributes matches his life values. We define this kind of uncertainty from a goal-oriented perspective, as life value reflects consumers' ultimate goals of consumption [11]. Consumption experience refers to consumer physical, social and psychological responses to product usage [22]. Life value should be achieved by a series of consumption experience on various product attributes [11].

Moreover, product uncertainty and lifestyle fit uncertainty can be empirically separated. For example, an e-commerce website accurately describes "the attributes and high quality of a brand of skirt", which means low product uncertainty. However, a consumer still doesn't know her consumption experience of the skirt (i.e., whether it suits her appearance) without trying; and thus can't assess whether the consumption experience matches her life value. She feels a high lifestyle fit uncertainty.

The distinction of lifestyle fit uncertainty and product fit uncertainty is as follows. The former focuses on consumption experience and life value, whereas the latter focuses on product attributes and consumer preference. The consumption experience depends on not only product attributes but also a consumer's individual differences, such as physical attributes, preferences, social status, etc. Individuals who vary in age may well look different in the same clothing. Life values (i.e., ideal life states) also differ from consumer preferences (i.e., more liking something than others), as the former is an ultimate consumption goal and stable, whereas the latter is 
short-time taste and can be changed easily [3, 19, 20]. Life values affect people's consumption preference, not versa visa $[3,21]$.

Low product fit uncertainty is a requisite but not a sufficient condition to reduce lifestyle fit uncertainty. For example, a woman may have a life value of being beautiful and confident. She tends to realize this ultimate consumption goal by shopping for clothes. To continue the example, let's assume she intends to buy a skirt online. The online pictures may show the fashionable design and bright colors of the skirt, as well as how beautiful a model looks in it. The woman may evaluate these attributes of the skirt as fitting well with her preferences and thus lowering the perceived product fit uncertainty. However, she still cannot predict her eventual consumption experience of the skirt, including the psychological and functional aspects, which also depend on her own characteristics, such as body style and appearance. Perhaps her body style and appearance are not suitable for this skirt according to the norms of her social network, and she may not appear as was her goal. The poor appearance resulting may reduce her confidence. Thus, low product fit uncertainty doesn't necessarily lead to good functional and psychological experience, which are necessary for realizing the woman's ultimate consumption goal: being beautiful and confident. The woman still has a high lifestyle fit uncertainty.

\subsection{IT-mediated lifestyle-centric service content from MECL perspective}

MECL [2] perspective from the marketing field posits that consumption behaviors are driven by consumers' lifestyles and describes their lifestylecentric decision-making processes. People do not buy products for the products' sake but for the consumption experience that the product attributes can bring and whether the experience can help them realize their life values [4]. Hence, lifestyle-centric marketing service content should provide the three aspects of information, including product attributes, consumption experiences and personal values, for facilitating consumers' decision-making [2, 11]. Moreover, in the e-service context, Tan et al. [14] defined IT-mediated service content as the functions available from IS used to assist users in completing various tasks. Based on the above literature, we define IT-mediated lifestyle-centric marketing service content of e-commerce live streaming as a series of IT-mediated service functions that deliver marketing information including product attributes, consumption experience and value to facilitate consumers' purchase decision-making [5].

These IT-mediated service functions are manifested as Internet celebrities use ICT tools of live streaming platforms to deliver information [5]. In e-commerce context, Internet celebrities, with product expertise, are deemed as socially endorsed charismatic (opinion) leaders who guide online consumers in making purchase decisions.

Thus, we integrate MECL perspective with three mechanisms (i.e., value internalization, vicarious learning and mean recommendation) of SCL theory [5, $23]$ to identify three components of service content: 1) IT-mediated value transmission, which consists of four IT functions transmitting values, 2) IT-mediated vicarious experience learning, which consists of four IT functions transmitting consumption experiences, 3) IT-mediated product presentation, which consists of four IT functions present product attributes [5].

\section{Theoretical model and propositions}

\subsection{Effect of product uncertainty and lifestyle fit uncertainty}

Based on the MECL theory [2, 11], consumer cognitive structure is top-down: value-consumption experience-product attributes. Life value (i.e., "end") is on the top level of the hierarchical cognitive structure. It reflects a consumer's ultimate consumption goal [3, 11]. Life value guides consumers to shape goaloriented consumption behavioral modes (i.e., lifestyle), and decides consumers' choices of products [2]. Products (i.e. means) are on the bottom of the structure. A consumer will decide to buy a product, only when he think that the attributes of a product bring him desired consumption experience; and the desired consumption experience match with his value [2, 11]. Before purchasing an experiential product, he need perfect information of its experience attributes and consumption experiences. However, experience attributes (e.g., what does a perfume smell) and consumption experience (e.g., I feel confident in using the perfume) are difficult to be presented in a straightforward manner online. They are indeed subjective and various because of individual difference [1]. Product uncertainty (description uncertainty and performance uncertainty) often exists online [9].

MECL theory explicitly assumes that consumers' goal-directed purchase decision-making is voluntary and conscious [11]. Consumer decisions are guided by the avoidance of the unpredictable outcomes and the search of positive consequences in online transactions [24]. Uncertainty on transaction outcomes should definitely reduce consumers' intention to buy. Huang and Colleague [1] suggested that providing information of product attributes and product experiences increase 
consumers' purchase intention at e-commerce websites. Hence, we propose:

Proposition 1a: Product uncertainty has a negative effect on consumers' purchase intentions on ecommerce websites.

Likewise, without perfect information of experience attributes (i.e., description uncertainty) and consumption experience (i.e., performance uncertainty), consumers can't assess whether their consumption experience match with their values. Hence, product uncertainty should increase lifestyle fit uncertainty. Based on the similar logic, Hong and Pavlou [10] found product unfamiliarity increased product fit uncertainty. Hence, we propose:

Proposition 1b: Product uncertainty has a positive effect on lifestyle fit uncertainty on e-commerce websites.

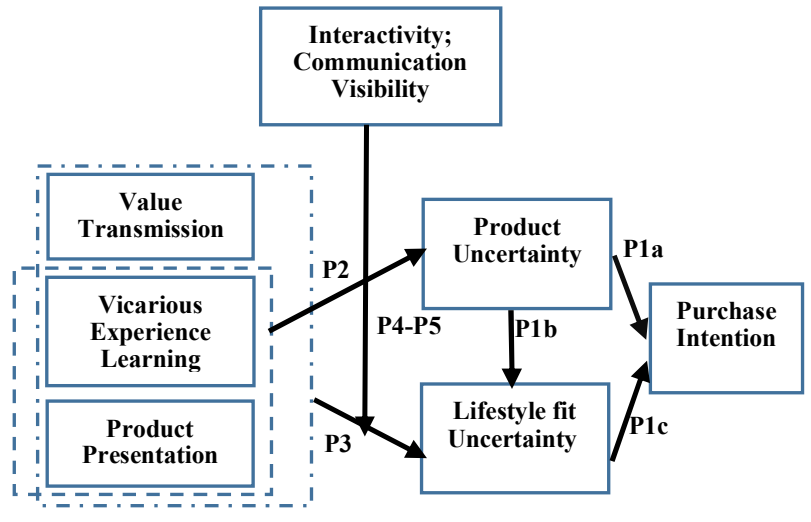

Figure 1. Theoretical model

MECL [2, 24] theory highlights that personal value guides consumers' choices of products. Consumption experience of a product is the more salient considerations in their purchase decisionmaking [4, 24]. People buy a product for the benefits of the product rather than for the product's sake. The attributes of the product are basic information only used to predict its benefits (i.e., consumption experience) [2]. Thus, whether the consumption experiences of selected products match with consumers' values should be more important predictor of consumers' purchase intention. Hence, we propose:

Proposition 1c: lifestyle fit uncertainty has a negative effect on consumers' purchase intentions on ecommerce websites.

\subsection{Antecedents of lifestyle fit uncertainty and product uncertainty}

Lifestyle fit uncertainty implies that a consumer not sure whether a product matches his life value. It is caused by his lack of three aspects of information: what is his life value? What consumption experience helps to realize the life value? What product attributes bring the consumption experience? Lack of the information is due to the following reasons: 1) IT limitation of e-commerce websites in describing experience attributes of experiential products and consumption experience; 2 ) true product information is disclosed due to sellers' lacking of expertise, unawareness or unwillingness; 3) consumers' unawareness of their own personal values or inability of inferring whether consumption experience of products matches their values. Product uncertainty pertains to consumers' information problems due to their difficulty in assessing product attributes and predicting consumption experience; and arises from the aforementioned reasons 1) and 2) [9].

To reduce lifestyle fit uncertainty and product uncertainty, the service content of e-commerce live streaming should mitigates the aforementioned drivers of uncertainty. First, the service content, consisting of service functions, is a marriage of Internet celebrities' behaviors and ICT capabilities [15], and thus compensate for the deficiency of ICTs in delivering experience attributes and consumption experience. Second, Internet celebrities are well-trained with product expertise and avoid marketers' inabilities of providing true information due to lacking of expertise. Third, the service content is lifestyle-centric, which not only presents product attributes but transfers consumption experience and values, which facilitate consumers to make purchase decisions effectively [9].

Moreover, the service content of e-commerce live streaming should consist of three functions which provide the three aspects of information (product attributes, consumption experience and value), respectively. We incorporate three mechanisms of SCL theory into MECL theory $[2,23]$ to identify three components of the service content and the specific service functions of each component. Based on the mean recommendation mechanism [23], we identify IT-mediated product presentation as the first component of the service content, which means that ICTs assist Internet celebrities in presenting not only search attributes (e.g., price or size) but experience attributes of products [2, 25]. It consists of four service functions to present four types of product attributes thoroughly [25]. Excepting for multimedia advertising, which allows an Internet celebrity to use symbol sets (e.g., pictures and videos) to present search attributes [26]. Other three functions can be used to present experience attributes of products, including visually salient attributes (e.g., color), tactilely salient (e.g., taste and smell) and intangible attributes (i.e., texture, origin of place and brand), respectively $[5,25]$. Specifically, visual control means that ICTs enable an Internet celebrity follow his online reviewers' requests 
to manipulate (e.g., move or rotate) a product so that the viewers can see the product from different angles and distances [27]. This function allows consumers control the process of inspecting the product and the video of the show synchronously demonstrates the process, which prevents the Internet celebrity from disguising exterior flaws of the product because of unwillingness or unawareness [9].

Third, vicarious tactile control means that ICTs enable an Internet celebrity follow online viewers' requests to tactilely interact (taste or smell) with a product and let these viewers know its tactilely salient attributes [5, 28]. For example, a consumer can't smell a bottle of Dior perfume online, and can't exactly know the smell from online comments. As different consumers have different description about the smell. Vicarious tactile control means that, after receiving the consumer's request ("please smell it"), the internet celebrity smells the perfume and describes "how it smells". The internet celebrity has product expertise, which avoid his inability of describing the smell objectively [9]. He shares similar preferences with the consumer and his description of the smell should be the same as that of the consumer $[29,30]$. Moreover, the consumer also can tell "whether the smell is good or not" by watching the internet celebrity's real facial expression and body language through the show. In this light, tactile salient attributes (e.g., smell) can be accurately presented online by this function.

Finally, spatial navigation provides telepresence that allows an Internet celebrity virtually "guides" consumers to move through environments (e.g., factories) and provide professional interpretation of product intangible attributes (e.g., origin of place and textures) $[5,31]$. Hence, IT-mediated product presentation consisting of four functions is proposed to avoid imperfect product information caused by marketers' inability, unwillingness and unawareness. More importantly, It is expected to reduce product uncertainty and also lifestyle fit uncertainty in terms of delivering perfect information of product attributes which are basis for predict consumption experience.

Proposition 2a: IT-mediated product presentation has a negative effect on product uncertainty.

Proposition 3a: IT-mediated product presentation has a negative effect on lifestyle fit uncertainty.

Based on vicarious learning mechanism [29, 30], we identify IT-mediated vicarious experience learning as the second component. It is defined as an Internet celebrity uses ICTs to demonstrate his consumption experience of using products and launch IT-mediated vicarious learning that enables his online viewers infer their own consumption experience of using the same products [29]. Vicarious learning mechanism consists of four factors [30], which are adapted into our research context to develop four functions of ITmediated vicarious experience learning.

First, analogical mapping means that ICTs help to match an Internet celebrity with an online viewer according to their similar features (e.g., life value, consumption preference or appearance) that are most predictive of their consumption experience $[29,30]$. As mentioned above, consumption experience depends on individual difference and is difficult to be transmitted online [1]. Different consumers looks and feels different when wearing the same skirt. Analogy mapping solves the problem of individual differences by allowing an online viewer to identify an internet celebrity as his vicarious model who share similarities with him. This is a key step to compensate for the limitation of traditional IT in delivering personal experience.

Second, trialability enables the vicarious model use ICTs to display how he try products according to the online viewer's requirements [32]. Third, vicarious experience demonstrability enable the vicarious model use ICTs to demonstrate the tangible and psychological experience of using a product to the viewer. The vicarious model's consumption experience is similar as that of the viewer, and thus it is called vicarious experience of the viewer [32]. Trialability and vicarious experience demonstrability avoid that the internet celebrity omits true information due to his inability, unwillingness and awareness. He has expertise and can provide professional interpretation of his experience. The processes of trying products and demonstrating experience are accordance with the viewer's requirements and synchronously monitored by the viewer through the live streaming show; and thus he has no opportunities to hide true experience information due to unwillingness or unawareness [10].

Fourth, transferring enables the internet celebrity, as a vicarious model, use ICTs to help the viewer infer his consumption experience of using the same product according to the vicarious consumption experience by analogy. Altogether, IT-mediated vicarious experience learning is proposed to reduce product uncertainty and also lifestyle fit uncertainty in terms of giving perfect information of consumption experience.

Proposition 2b: IT-mediated vicarious experience learning has a negative effect on product uncertainty.

Proposition 3b: IT-mediated vicarious experience learning has a negative effect on lifestyle fit uncertainty.

Based on value internalization mechanism [33, 34], we identify IT-mediated value transmission as the third component. It is defined as ICTs assist an Internet celebrities in transmitting ideal life values and the ways of realizing the values [33]. Value internalization mechanism consists of four factors [34], which are 
adapted into our research context to develop four functions of IT-mediated value transmission. Vision means that ICTs assist an Internet celebrities in transmitting ideal life goals to arouse online viewers' unfilled needs. Personalization means that ICTs enable the Internet celebrity rapidly know and address viewers' unfilled needs. Consumption cues means that ICT assists an Internet celebrity in recommending to viewers what products should be bought and how to buy online so as to meet their unfilled needs. Finally, inspiration means that ICTs enable an Internet celebrity has inspirational communication with online viewers to boost their confidence in meeting their unfilled needs by using the recommended products.

Overall, vision delivers the information of a life value. Personalization, consumption cues and inspiration address why and how the life value matches with the recommended products. The information helps a viewer to tell whether the life value transmitted by a live steaming show is congruent with his own life value; and further helps him to forge a link between his own life value with the recommended products so that the viewer can better assess whether the consumption experience of the recommended products matches his own life value or not. Hence, we propose:

Proposition 3c: IT-mediated value transmission has a negative effect on lifestyle fit uncertainty.

\subsection{The moderating role of ICT-enabled information retrieval capabilities}

ICT-enabled information retrieval system mainly provides two different ways for online viewers to acquire the information delivered by the service content of e-commerce live streaming. This system is afforded by two ICT capabilities: interactivity and communication visibility $[16,17]$.

3.3.1 Interactivity. Interactivity refers to an ICT capability in a live streaming platform that enables online viewers have synchronous and two-way communication with the internet celebrity in a live streaming show $[16,35]$. In other words, interactivity allows synchronous information exchange between an online viewer and his internet celebrity [16]. Interactivity is afforded by a set of IT tools in live streaming platforms, such as public scrolling text, oneon-one text, video, and audio [5]. "Public scrolling text" allows an online viewer (consumer) to type his inquiry (e.g., requiring the internet celebrity to try a product) or other message in a dialog box and the inquiry can be seen by all online viewers as well as the internet celebrity. "One-on-one text" allows an online reviewer to send an inquiry that can only be seen by the internet celebrity. After receiving the viewer's message, the internet celebrity will reply his inquiry by video and audio in the show synchronously $[5,16]$.

When interactivity is high, the information of product attributes delivered through IT-mediated product presentation will be synchronously and rapidly obtained by an online viewer [16]. The information of product attributes will be useful to the viewer in inferring product benefits and whether the benefits match his life value, which reduces his lifestyle fit uncertainty [2]. Moreover, when interactivity is high, the viewer is more likely to believe that the information delivered by IT-mediated product presentation is "true" and "perfect", as the information must be provided according to all of his inquiries and meet his information need. The belief will dismiss the viewer's doubt that the Internet celebrity disclose product information because of unawareness or unwilling [9]. This will decrease his lifestyle fit uncertainty.

By contrast, low interactivity inhibits a viewer from sending inquiries (like in TV shopping show) to and obtaining replies from an Internet celebrity [16, 35]. Under such a condition, the information of product attributes delivered by IT-mediated product presentation can't be obtained by the viewer, or may not be what the viewer need even if he receive the information. What's more, when interactivity is low, the viewer can not send inquiries and may doubt that some of "true" product information be concealed due to the Internet celebrity's unwillingness or unawareness [9]. Lacking of the information of product attributes make the viewer unable to infer product benefits and whether the benefits match his life value, which increases his lifestyle fit uncertainty [2].

Proposition 4a: Interactivity moderates the negative effect of IT-mediated product presentation on lifestyle fit uncertainty in that the negative effect will be higher when interactivity is high than when it is low.

Likewise, when interactivity is high, the information of vicarious consumption experience delivered by IT-mediated vicarious experience learning will be synchronously obtained by an online viewer $[16,35]$. This information will be used by him to infer whether his consumption experience of the product matches his value, which decreases his lifestyle fit uncertainty [2]. Moreover, when interactivity is high, the viewer is more likely to believe that the consumption experience of a product transmitted by the live streaming service is "true" and "perfect", as the internet celebrity try the product and describe its consumption experience according to all of his requirements $[9,10]$. This belief dismisses his doubt that some undesirable experience may be concealed and deceases his lifestyle fit uncertainty. 
On the contrary, when interactivity is low, the vicarious consumption experience delivered by the service can't be accessed by the viewer [16]. Or it may fail to meet the viewer's need as he can't send requirements and internet celebrity tries the product as well as demonstrates the usage experience in a way that is not what he want. This may make the viewer be worry about the authenticity and integrality of the usage experience presented by the service. Lacking of perfect information about consumption experience will increase his lifestyle fit uncertainty.

Proposition $4 \boldsymbol{b}$ : Interactivity moderates the negative effect of IT-mediated vicarious experience learning on lifestyle fit uncertainty in that the negative effect will be higher when interactivity is high than when it is low.

When interactivity is high, the life value delivered by IT-mediated value transmission will be efficiently accessed by an online viewer, which facilitates him to tell whether the value is acceptable and whether the value match with the consumption experience of some products [16, 35]. This reduces his lifestyle fit uncertainty. Moreover, high interactivity enables an online viewer send various personal information (e.g., life status, ideal life goal and unfilled needs) to an Internet celebrity by synchronous communication [5]. This process allows him believe that the Internet celebrity "know about him very well". Under such a condition, information delivered by IT-mediated value transmission may be perceived by the viewer as tailored information for meeting his special needs. The personalized information of life value especially reduces his lifestyle fit uncertainty.

By contrast, when interactivity is low, the valuerelated information delivered by the service can't be synchronously obtained by a viewer. Lacking of value information will cause a viewer, who doesn't recognize his potential value, has a high lifestyle fit uncertainty when choosing products. Hence, we propose:

Proposition $4 \boldsymbol{c}$ : Interactivity moderates the negative effect of IT-mediated value transmission on lifestyle fit uncertainty in that the negative effect will be higher when interactivity is high than when it is low.

3.3.2 Communication visibility. In general, there are a great number (e.g., 8000) of consumers synchronously watching a 2-hour live streaming show. Interactivity only enables a tiny fraction of (e.g., 50) online viewers directly communicate with the internet celebrity and acquire information in the show. The biggest advantageous of communication visibility is that it allows the remaining online consumers (e.g., 7500) synchronously acquire information they need by observing communication between the tiny fraction of viewers and the Internet celebrity in the show $[5,17]$. Moreover, communication visibility enables the great number of online viewers acquire useful information with less time (i.e., within 2 hours) and effort input (i.e., watching is easier than typing) [35]. The more people obtain useful marketing information, the more purchase decisions they make. That's why live streaming greatly promotes e-commerce purchasing online. This situation won't be practical offline.

When communication visibility is high, it allows a consumer, as a third-party, to see all inquiries of product attributes (e.g., requiring the internet celebrity to show the camera of a cellphone) from other online viewers and also watch how the Internet celebrity present the product attributes according to these requirements in the show [17]. Under such a context, the viewer, as a third-party, can easily find which inquiries from others are similar as his own so as to pay more attention on the internet celebrity's responses to these similar inquires (e.g., could you show the camera of the cellphone?) [5]. By doing this, he can effectively select what he needs from the information delivered by IT-mediated product presentation and the useful information of product attributes will help him to reduce lifestyle fit uncertainty [9]. Moreover, if he watches the internet celebrity responds to diverse inquiries from different viewers, he is more likely to believe that the information provided by the show is "true" and "perfect". As the internet celebrity has no opportunity to withhold product information because of unwillingness or unawareness. This perception of him also may reduce his lifestyle fit uncertainty $[9,10]$.

By contrast, low communication visibility makes the viewer, as a third-party, be disable to see others' inquiries and thus don't understand the internet celebrity's answers sometimes. For example, when he watches the playback of a live streaming show, in which the public scrolling text screen and other online viewers' questions disappear. When he see that the internet celebrity say "yes" to reply another online viewer's question, he can't understand what does "yes" mean without seeing the question. Because of this, he may obtain little useful information delivered by ITmediated product presentation. Lacking of information about product attributes may increase his lifestyle fit uncertainty $[9,10]$. Hence, we propose:

Proposition 5a: Communication visibility moderates the negative effect of IT-mediated product presentation on lifestyle fit uncertainty in that the negative effect will be higher when communication visibility is high than when it is low.

When communication visibility is high, the consumer, as a third-party, can easily see other online viewer' inquires related to consumption experience of some products and find which inquiries are similar as his own so as to pay more attention on the internet 
celebrity's responses to these similar inquires (e.g., Do you feel comfortable on this shoes?) [17, 35]. By doing this, he can easily obtain needed information of vicarious consumption experience transmitted from ITmediated vicarious experience learning, and the useful experience-related information reduces his lifestyle fit uncertainty $[9,10]$. By contrast, when communication visibility is low, the viewer can't quite understand the internet celebrity's answers without knowing the corresponding questions, and thus may obtain little useful information of consumption experience delivered from the show. This may increase his lifestyle fit uncertainty. Hence, we propose:

Proposition 5b: Communication visibility moderates the negative effect of IT-mediated vicarious experience learning on lifestyle fit uncertainty in that the negative effect will be higher when communication visibility is high than when it is low.

When communication visibility is high, if an internet celebrity transmits value-related information to fit other online viewers' needs, the third-party can clearly understand these information and select useful value information for his own use. This reduces his lifestyle fit uncertainty. When communication visibility is low, the value-related information may not be understood very well by the third-party. Obtaining imperfect value-related information from the show leads to a high lifestyle fit uncertainty.

Proposition 5c: Communication visibility moderates the negative effect of IT-mediated value transmission on lifestyle fit uncertainty in that the negative effect will be higher when communication visibility is high than when it is low.

\section{Discussion}

By integrating MECL theory, SCL theory and product uncertainty theory $[2,9,10,23]$, this study develops a theoretical framework to show: First, lifestyle fit uncertainty mediates the effect of product uncertainty on purchase intention and may be the most serious problem threatening online purchase intention. Three components of IT-mediated lifestyle-centric marketing service content and two ICT-enabled information retrieval capabilities mitigate the lifestyle fit uncertainty.

The theoretical implications include: First, this paper conceptualizes lifestyle fit uncertainty as a new type of online uncertainty that is a major barrier to ecommerce purchasing. Despite that consumers' purchase decisions are driven by the match between their lifestyles and products [2, 11], researchers have not previously developed a concept to describe this phenomenon. The conceptualization of lifestyle fit uncertainty offers an initial theoretical foundation to guide future research on this phenomenon. Second, product uncertainty theory posits that product uncertainty is a well-known predictor of online transactions [9]. Our theoretical model demonstrates that product uncertainty affects purchase intention through lifestyle fit uncertainty. Thus, we introduced a more important predictor to online transaction literature. Third, this paper contributes to uncertainty theories by explaining "what" affects uncertainty [36]. We integrate MECL theory, SCL theory and product uncertainty theory $[2,9,23]$ to identify three components of IT-mediated lifestyle-centric marketing service content as the antecedents of lifestyle fit uncertainty and product uncertainty. Finally, our theoretical model also extends uncertainty literature by explaining "why" and "how" two ICT-enabled information retrieval capabilities, as moderators, help reduce consumers' lifestyle fit uncertainty online [36].

Our research findings should also contribute to practice. First, given that lifestyle fit uncertainty is major barrier to e-commerce purchasing, online marketing services should provide perfect information to reduce online consumers' lifestyle fit uncertainty. Second, our research suggests that effective ITmediated marketing service content, should be lifestyle-centric, which include value transmission, vicarious experience learning and product presentation. This finding will facilitate practitioners to identify missing marketing service content and related IT service functions. Third, our research also shows that online marketing platforms should pay more attention on the development of IT-enable information retrieval capabilities (e.g., interactivity and communication visibility). This will enable more online consumers synchronously obtain needed marketing information effectively and efficiently so as to reduce their lifestyle fit uncertainty and improve their purchase intention.

This study has several limitations that should be addressed by future research. First, this study theoretically conceptualizes the new concept of lifestyle fit uncertainty but does not clarify how to measure it. Future research should develop its measurement so that more empirical studies can focus on it. Second, this research only provides theoretical justification of the studied model and calls for future research to test the model with empirical data. Third, our theoretical framework is proposed in the context of e-commerce live streaming, and future research should examine whether this framework could be applied in other e-commerce contexts.

\section{References}

[1] P. Huang, N.H. Lurie, and S. Mitra, "Searching for Experience on the Web: An Empirical Examination of Consumer Behavior for Search and Experience Goods", 
Journal of Marketing, 2009, pp. 55-69.

[2] V.A. Zeithaml, "Consumer Perceptions of Price, Quality,and Value: A Means-end Model and Synthesis of Evidence", Journal of Marketing, 1988, pp. 2-22.

[3] J.T. Plummer, "The Concept and Application of Lifestyle Segmentation", Journal of Marketing, 1974, pp. 33-37.

[4] L. Xiao, Z.X. Guo, and J. DAmbra, "A Typology of Online Group Buyers: Using Means-end Structures for Benefit Segmentation", Thirty Fifty International Conference on Information Systems, Auckland, 2014, pp.1-20.

[5] Z.J. Chen, I. Benbasat, and R. Cenfetelli, "Grassroots Internet Celebrity Live Streaming" Activating IT-Mediated Lifestyle Marketing Services at e-Commerce Websites, Thirty-eighth International Conference on Information Systems, Seoul, 2017, pp. 20-28. ${ }^{4}$

[6] G.A. Akerlof, "The Market for "Lemons": Quality Uncertainty and the Market Mechanism", Quarterly Journal of Economics, 1970, pp. 488-500.

[7] A. Ghose, "Internet Exchanges for Used Goods: An Empirical Analysis of Trade Patterns and Adverse Selection", MIS Quarterly, 2009, pp. 263-291.

[8] P.A. Pavlou, H. Liang, and Y. Xue, "Understanding and Mitigating Uncertainty in Online Buyer-Seller Relationships: A Principal Agent Perspective", MIS Quarterly, 2007, pp. 105-136.

[9] A. Dimoka, Y. Hong, and P.A. Pavlou, "On Product Uncertainty in Online Markets: Theory and Evidence", MIS Quarterly, 2012, pp. 395-426.

[10] Y. Hong, and P.A. Pavlou, "Product Fit Uncertainty in Online Markets: Nature, Effects, and Antecedents", Information Systems Research, 2014, pp. 328-334.

[11] K. Brunsø, J. Scholderer, and K.G. Grunert, "Closing the Gap between Values and Behavior-a means-end theory of Lifestyle", Journal of Business Research, 2004, pp. 665-670.

[12] N. Ahmad, A. Omar, and T. Ramayah, "Consumer Lifestyles and Online Shopping Continuance Intention", Business Strategy Series, 2010, pp. 227-243.

[13] A. Mishra, S.B. Dash, and D. Cyr, "Linking User Experience and Consumer-based Brand Equity: the Moderating Role of Consumer Expertise and Lifestyle", Journal of Product \& Brand Management, 2014, pp. 333-348. [14] C.W. Tan, I. Benbasat, and R.T. Cenfetelli, "ITmediated Customer Service Content and Delivery in Electronic Government: An Empirical Investigation of the Antecedents of Service Quality”, MIS Quarterly, 2013, pp. 77-109.

[15] L.M. Maruping, and R. Agarwal, "Managing Team Interpersonal Processes through Technology: A TaskTechnology Fit Perspective", Journal of Applied Psychology, 2004, pp. 975-990.

[16] C.X. Ou, P. Pavlou, and R. Davison, "Swift Guanxi in Online Marketplaces: The Role of Computer-Mediated Communication Technologies", MIS Quarterly, 2014, pp. 209-230.

[17] P.M. Leonardi, "Social Media, Knowledge Sharing, and Innovation: Toward a Theory of Communication Visibility", Information Systems Research, 2014, pp. 796-816.

[18] F.H. Knight, Risk, Uncertainty and Profit, Houghton Mifflin, New York, 1921.

[19] J.W. Overby, and E.J. Lee, "The Effects of Utilitarian and Hedonic Online Shopping Value on Consumer
Preference and Intentions", Journal of Business Research, 2006, pp. 1160-1166.

[20] M. P. Gardner and K. Junyong, "Better Moods for Better Eating?: How Mood Influences Food Choice", 2014, pp. 320-335.

[21] C. Janiszewski, K. Andrew and N. T. Tavassoli, "The Influence of Selective Attention and Inattention to Products on Subsequent Choice", Journal of Marketing Research, 2013, pp. 1258-1275.

[22] B.H., Schmitt, Experiential Marketing, the Free Press, New York, 1999.

[23] B. Shamir, R.J. House, and M.B. Arthur, "The Motivational Effect of Charismatic Leadership: A Selfconcept Based Theory", Organization Science, 1993, pp. 577-594.

[24]T.J. Reynolds, and J.C. Olson, Understanding Consumer Decision Making: The Means-end Approach to Marketing and Advertising Strategy, Lawrence Erlbaum, Mahwah, 2001 [25] J. Nielsen, Designing Web Usability: The Practice of Simplicity, New Riders, Indianapolis, 1999.

[26] Z. Jiang, and I. Benbasat, "The Effects of Presentation Formats and Task Complexity on Online Consumers' Product Understanding”, MIS Quarterly, 2007, pp. 475-500.

[27] Z. Jiang, and I. Benbasat, "Virtual Product Experience: Effects of Visual and Functional Control of Products on Perceived Diagnosticity and Flow in Electronic Shopping", Journal of Management Information Systems, 2004, pp. 111147.

[28] L.A. Sutton, "The Principle of Vicarious Interaction in Computer-mediated Communications", International Journal of Educational Telecommunications, 2001, pp. 223-242.

[29] C.C. Manz, and H.P. Sims, "Vicarous Learning: The Influence of Modeling on Organizational Behavior", Academy of Management Review, 1981, pp. 105-113.

[30] M.Y. Yi, and F.D. Davis, "Developing and Validating an Observational Learning Model of Computer Software Training and Skill Acquisition", Information systems research, 2003, pp.146-169.

[31] H.R. Li, T. Daugherty, and F. Biocca, "Characteristics of Virtual Experience in Electronic Commerce: A Protocol Analysis", Journal of Interactive Marketing, 2001, pp. 13-30. [32] G.C. Moore, and I. Benbasat, "Development of an Instrument to Measure the Perceptions of Adopting an Information Technology Innovation", Information Systems Research, 1991, pp. 192-222.

[33] M.E. Brown, and L.K. Treviño, "Leader-Follower Values Congruence: Are Socialized Charismatic Leaders Better Able to Achieve It?", Journal of Applied Psychology, 2009, pp. 478-490.

[34] S.A. Kirkpatrick, and E.A. Locke, "Direct and Indirect Effects of Three Core Charismatic Leadership Components on Performance and Attitudes", Journal of Applied Psychology, 1996, pp. 36-51.

[35] J.W. Treem and P. M. Leonardi, Social Media Use in Organizations: Exploring the Affordances of Visibility, Editability, Persistence, and Association, Comm. Yearbook, 2012, pp.143-189.

[36] D.A. Whetten, "What Constitutes a Theoretical Contribution?", Academy of Management Review, 1989, pp. 490-495.

\footnotetext{
${ }^{4}$. This paper is related to [5].
} 